\title{
Factors Associated with Osteoporosis Screening and Recommendations for Osteoporosis Screening in Older Adults
}

\author{
Smita Nayak, MD' , Mark S. Roberts, MD, MPP' and Susan L. Greenspan, MD² \\ 'School of Medicine, Department of Medicine, Division of General Internal Medicine, Section of Decision Sciences and Clinical Systems \\ Modeling, University of Pittsburgh, Pittsburgh, PA, USA; ${ }^{2}$ School of Medicine, Department of Medicine, Division of Endocrinology and \\ Metabolism and Division of Geriatric Medicine, University of Pittsburgh, Pittsburgh, PA, USA.
}

BACKGROUND: Osteoporosis screening rates are low, and it is unclear which patient factors are associated with screening and physician recommendations for screening.

OBJECTIVE: To identify patient characteristics associated with osteoporosis screening recommendations and receipt of screening in older adults.

DESIGN: Cross-sectional mailed survey.

PARTICIPANTS: Women and men $\geq 60$ years old living in or near western Pennsylvania.

MEASUREMENTS: Sociodemographic characteristics and osteoporosis-related data, including risk factors, physician recommendations for screening, and receipt of screening. Multivariable logistic regression analyses were performed to determine odds ratios for receipt of screening and screening recommendations for individuals with particular osteoporosis risk factors, adjusting for sociodemographic and other risk factors.

RESULTS: Surveys were completed by 1,268 of the 1,830 adults to whom surveys were mailed (69.3\%). Most respondents were white (92.9\%), female (58.7\%), and believed they were in good to excellent health (88.2\%). Only 47.6\% said their physician recommended osteoporosis screening, and $62.6 \%$ of all respondents reported being screened. Screening recommendations were less likely for older respondents than younger ones (OR, 0.87 per 5-year increase in age; 95\% CI, 0.770.97). Individuals with osteoporosis risk factors of a history of oral steroid use for $>1$ month, height loss $>2.54 \mathrm{~cm}$, or history of low-trauma fracture were no more likely to report screening recommendations than individuals without these characteristics. Receipt of screening was no more likely for more elderly respondents or respondents with a history of oral steroid use for $>1$ month than for respondents without these characteristics.

CONCLUSIONS: Individuals with several known osteoporosis risk factors are not being sufficiently targeted for screening.

Received August 8, 2008

Revised February 3, 2009

Accepted February 5, 2009

Published online March 10, 2009
KEY WORDS: osteoporosis; screening; geriatrics; survey research.

J Gen Intern Med (24)5:585-91

DOI: $10.1007 / \mathrm{s} 11606-009-0936-6$

(C) Society of General Internal Medicine 2009

\section{INTRODUCTION}

Osteoporosis is common and costly, affecting 10 million women and men in the United States, with direct costs of $\$ 17$ billion in 2005. ${ }^{1-3}$ Studies suggest that approximately one-half of all postmenopausal women and one-quarter of white men over 60 years of age will sustain an osteoporotic fracture in their lifetime. ${ }^{4,5}$ Consequences of osteoporosis can be severe, including chronic pain, loss of ability to ambulate, nursing home placement, and mortality. ${ }^{6-9}$

There are many risk factors for osteoporosis in older adults. The Study of Osteoporotic Fractures, a large, prospective US study of close to 10,000 women aged 65 and older, identified 14 clinical risk factors for osteoporotic hip fracture in multivariable models: age, maternal hip fracture, personal history of any fracture since age 50, height, poor self-rated health, no weight gain, hyperthyroidism, not walking for exercise, lack of ambulation, inability to rise from a chair, poor vision, high resting pulse, and current use of benzodiazepines, anticonvulsants, or caffeine. ${ }^{10}$ The World Health Organization recently released a fracture risk assessment tool (FRAX) that incorporates clinical risk factors identified from populationbased cohorts to predict individuals' 10-year probability of osteoporotic fracture. ${ }^{11}$ Clinical risk factors assessed by the FRAX tool are age, sex, history of prior spontaneous or lowtrauma fracture, weight, height, parental history of hip fracture, current smoking, alcohol intake 3 or more units per day, presence of a medical condition associated with secondary osteoporosis (e.g., hypogonadism), oral glucocorticoid use for 3 or more months (ever), and rheumatoid arthritis. ${ }^{11}$

Several organizations, including the US Preventive Services Task Force (USPSTF), the American College of Physicians (ACP), and the National Osteoporosis Foundation (NOF), recommend that clinicians screen older adults for osteoporosis. ${ }^{12-14}$ The USPSTF recommends that all women aged 65 and older should be screened for osteoporosis. ${ }^{12}$ The 2008 NOF guidelines suggest that all women aged 65 and older and men aged 70 and older be screened. ${ }^{13}$ The ACP recommends that clinicians periodically assess men aged 70 and older for osteoporosis risk factors and perform dual- 
energy X-ray absorptiometry in those who are at increased risk and are candidates for medical therapy. ${ }^{14}$ These organizations also recommend that younger individuals with additional osteoporosis risk factors be screened. ${ }^{12-14}$ Despite these guidelines, studies indicate that most individuals with osteoporosis remain undiagnosed and untreated. ${ }^{15-17}$

The objective of our study was to identify patient characteristics associated with physician recommendations for osteoporosis screening and receipt of screening in older adults. We hypothesized that individuals with known osteoporosis risk factors of older age, female sex, white race, family history of osteoporosis, low body weight, current smoking, heavy alcohol use, history of oral steroid use, height loss over the lifetime, and history of a low-trauma fracture would be more likely to receive a screening recommendation or report screening. We also hypothesized that individuals with higher self-rated health status, higher educational attainment, use of arms to get up from a chair most of the time, or history of a recent fall would be more likely to receive screening or a screening recommendation.

\section{METHODS}

\section{Study Participants and Procedures}

We performed a cross-sectional survey of 1,830 women and men who were 60 years of age or older, were living in or near western Pennsylvania, and were enrolled in the university's Claude D. Pepper Registry for studies on mobility and balance in older adults. The National Institutes of Health and the University of Pittsburgh developed the Claude D. Pepper Center to investigate mobility and balance in old age. To further their mission, the Claude D. Pepper Center developed the Pepper Center Research Registry, a list of people who have consented to be contacted for participation in research studies. Individuals had been recruited for this registry through community events, newspaper and TV advertisements, other clinical studies, targeted mailings to voter registration lists in low-income neighborhoods or neighborhoods enriched with minority elderly, and mailings to university alumni, faculty, and staff. Registry recruitment began in May of 2005. Approximately one-third of participants were recruited from other clinical studies for which they were ineligible, one-third were recruited from mailings to University of Pittsburgh alumni, faculty, or staff, and the remainder were recruited from community events, advertisements, and mailings.

Individuals who expressed interest in the registry completed a 15-20-min interview in which they provided basic health information. Most interviews were completed by telephone; individuals recruited at community events completed interviews in person. Eligibility for the registry was simply based on age and residence, which were established in this interview. People planning to move, on hospice, in a skilled nursing facility, or unable to do the phone interviews were excluded. Everyone else was eligible.

Approximately $68 \%$ of individuals who expressed interest in the Pepper Registry and were contacted subsequently enrolled. The most common reason for lack of enrollment after contact was disinterest after learning more about the registry. Retention in the registry has been excellent; only about 10\% of the sample has been lost to follow-up.

In November 2007, we mailed all individuals who were enrolled in the registry a 44-item survey, information describing the purpose of our study and assurance that survey responses would remain anonymous, and a prepaid return envelope. Of the 1,830 individuals enrolled in the registry at this time, mean age was $74,60.3 \%$ were female, $89.3 \%$ were white, and $76.7 \%$ had completed college. Only one mailing was performed, and no incentives were used or reminders were sent. We collected completed surveys over a 6-month period, and two individuals independently entered all survey responses into a database and validated the data to ensure integrity.

The survey asked respondents about sociodemographics, knowledge of osteoporosis, osteoporosis risk factors, mobility, falls, and health beliefs about osteoporosis. It also asked whether respondents had a personal history of osteoporosis, had received a recommendation for osteoporosis screening from their physician, and had been screened. The Appendix includes survey questions relevant to this study.

We received approval from the University of Pittsburgh Institutional Review Board prior to initiation of this study.

\section{Statistical Analysis}

We computed descriptive statistics for each survey item. We also performed logistic regression analyses to determine if there were associations between each of the two response variables (receipt of a recommendation for osteoporosis screening and receipt of screening) and the following potential explanatory variables: age (coded in 5-year increments), sex, self-reported race (white vs black), educational level (completed college vs did not complete college), family history of osteoporosis, self-rated health status (poor/fair vs good/very good/ excellent), weight (coded in increments of $11.4 \mathrm{~kg}$, or 25 pounds), current smoking, alcohol intake (3 or more drinks in one sitting at least 4 times per week vs less), history of oral steroid use for $>1$ month (ever), height loss $>2.54 \mathrm{~cm}$ ( 1 inch) over the lifetime, use of arms to get up from a chair most of the time, history of a fall within the past 5 years, and history of a low-trauma fracture (fracture resulting from a fall from standing height or less).

We included individual explanatory variables that showed a significant association with each response variable $(P \leq 0.10)$ as variable candidates in stepwise, backward selection, multivariable logistic regression models. We checked for evidence of interactions between variables and multicollinearity. We tested all possible two-way interaction products between individual explanatory variables included in the multivariable models. We considered variables and interaction terms with $P$ values of $\leq$ 0.05 to be significant in the final multivariable models. We reran all logistic regression analyses for the subset of our population including only women aged 65 and older and men aged 70 and older (individuals for whom screening is recommended in many guidelines). ${ }^{12-14}$ We used Stata version 10.0 (StataCorp, College Station, TX) to perform all analyses.

\section{RESULTS}

\section{Characteristics of Survey Respondents}

Of the 1,830 individuals to whom surveys were sent, 1,268 $(69.3 \%)$ responded (Table 1$)$. Respondents had a mean age of 73.3 years (range, 60-93; SD 7.3) and a mean weight of $76.9 \mathrm{~kg}$ (range, 42.6-147.4; SD 16.9). Most respondents were female 
Table 1. Characteristics of the Survey Respondents ${ }^{*} \dagger$

\begin{tabular}{|c|c|}
\hline Characteristics & Number (\%) \\
\hline \multicolumn{2}{|l|}{ Sociodemographic characteristics } \\
\hline Female sex & $664(58.7)$ \\
\hline White race & $1,148(92.9)$ \\
\hline Completed college & $926(75.0)$ \\
\hline \multicolumn{2}{|l|}{ Osteoporosis-related characteristics } \\
\hline Has heard of osteoporosis & $1,215(96.1)$ \\
\hline Has received physician recommendation for screening & 594 (47.6) \\
\hline Has been screened or tested for osteoporosis & $783(62.6)$ \\
\hline Has been diagnosed with osteoporosis & $283(22.6)$ \\
\hline Has had a low-trauma fracture (fracture resulting from a fall from standing height or less) & $236(18.8)$ \\
\hline Has a family history of osteoporosis & $292(23.8)$ \\
\hline \multicolumn{2}{|l|}{ Other health-related characteristics } \\
\hline Has a high self-rated health status (rated as good, very good, or excellent) & $1,114(88.2)$ \\
\hline Is a non-smoker & $1,248(98.7)$ \\
\hline Has a history of alcohol use $\geq 4$ times per week, $\geq 3$ drinks at a time & $32(2.6)$ \\
\hline Has a history of oral steroid use for more than 1 month & $103(8.2)$ \\
\hline Has experienced a height loss $>2.54 \mathrm{~cm}(1 \mathrm{inch})$ over the lifetime & 435 (35.3) \\
\hline Uses arms to get up from a chair most of the time & $460(36.8)$ \\
\hline Has fallen within the past 5 years & $609(48.6)$ \\
\hline
\end{tabular}

*There were 1,268 survey respondents. However, there were missing data for each of the characteristics listed in this table. The percentages shown here reflect the percentages of individuals who responded to the question about the characteristic listed. The percentage of missing data for sex was $10.8 \%$, but percentages of missing data for other characteristics were below 4\%. When we compared the gender distribution of survey respondents (58.7\% female, $41.3 \%$ male) to that of all registry participants (60.3\% female, $39.7 \%$ male), there was no significant difference ( $P=0.27)$

$\dagger$ Mean age of respondents was 73.3 years (range, 60-93; SD 7.3). Mean weight was 76.9 kg (range, 42.6-147.4; SD 16.9)

$(58.7 \%)$, white $(92.9 \%)$, had completed college $(75.0 \%)$, and believed that they were in good to excellent health $(88.2 \%)$. Fewer than half $(47.6 \%)$ said that they had received a physician recommendation for screening. Of the total group, $62.6 \%$ reported being screened, and $22.6 \%$ reported being diagnosed with osteoporosis. Of women aged 65 and older and men aged 70 and older, $50.2 \%$ said they had received a physician recommendation for screening, and $66.0 \%$ of individuals in this age group reported being screened.

\section{Bivariate Associations}

Results of bivariate logistic regression analyses for receipt of a physician recommendation for osteoporosis screening and receipt of osteoporosis screening are shown in Table 2. Individual factors significantly associated with receipt of a physician recommendation for osteoporosis screening included age, female sex, white race, family history of osteoporosis, weight, heavy alcohol intake, oral steroid use for $>1$ month, height loss $>2.54 \mathrm{~cm}$, use of arms to get up from a chair, fall within the past 5 years, and history of a low-trauma fracture. Individual factors significantly associated with receipt of screening included female sex, family history of osteoporosis, weight, heavy alcohol intake, oral steroid use for $>1$ month, height loss $>2.54 \mathrm{~cm}$, fall within the past 5 years, and history of a lowtrauma fracture.

\section{Multivariable Models}

Receipt of Osteoporosis Screening Recommendation. The receipt of a physician recommendation for osteoporosis screening was significantly associated with age, sex, weight, race, family history of osteoporosis, and use of arms to get up from a chair (Table 3). Respondents were less likely to report receiving a recommendation for screening if they were older or had a higher weight. They were more likely to report receiving a recommendation for screening if they were female, were white, had a family history of osteoporosis, or reported using their arms most of the time to get up from a chair. Because of multicollinearity, we had to remove two interaction terms from the model, namely, the interactions between family history and race, and sex and race. Thus, we could not test all possible interactions between the variables associated with screening recommendation. Of the interactions we tested (all remaining possible interaction products between explanatory variables), none were statistically significant.

Receipt of a physician recommendation for osteoporosis screening was not significantly associated with risk factors of oral steroid use for $>1$ month, height loss $>2.54 \mathrm{~cm}$, history of low-trauma fracture, heavy alcohol consumption, or smoking. When we repeated bivariate and multivariable logistic regression analyses for only women aged 65 and older and men age 70 and older, we found similar results (same variables retained in the receipt of screening recommendation multivariable model, with same direction of association and similar strength of association) with the exception of family history of osteoporosis not being retained in the final multivariable model.

Receipt of Osteoporosis Screening. The receipt of osteoporosis screening was significantly associated with sex, weight, family history of osteoporosis, history of low-trauma fracture, and height loss $>2.54 \mathrm{~cm}$ (Table 3). Respondents were more likely to report prior osteoporosis screening if they were female, had a family history of osteoporosis, or had a history of low-trauma fracture. Respondents were less likely to report prior screening if they had a higher weight. There was a significant positive interaction between loss of height $>2.54 \mathrm{~cm}$ and weight (Table 3). When we included this interaction in the model, loss of height by itself was not a significant predictor of receipt of screening; that is, loss of height was only associated with receipt of screening for individuals of higher weight. There was no evidence of multicollinearity in this model. 
Table 2. Bivariate Associations of Patient Characteristics with Osteoporosis Screening Recommendation and Receipt of Screening

\begin{tabular}{|c|c|c|c|c|}
\hline \multirow[t]{3}{*}{ Explanatory variables } & \multicolumn{4}{|l|}{ Response variables } \\
\hline & \multicolumn{2}{|c|}{$\begin{array}{l}\text { Physician recommendation for } \\
\text { osteoporosis screening }\end{array}$} & \multicolumn{2}{|c|}{$\begin{array}{l}\text { Receipt of osteoporosis } \\
\text { screening }\end{array}$} \\
\hline & OR $(95 \% \mathrm{Cl})$ & $P$ value & OR $(95 \% \mathrm{Cl})$ & $P$ value \\
\hline Increased age (in 5-year increments) & $0.90(0.84-0.97)$ & 0.01 & $0.99(0.91-1.07)$ & 0.75 \\
\hline Female sex & $17.10(12.43-23.52)$ & $<0.001$ & $14.09(10.49-18.94)$ & $<0.001$ \\
\hline White race & $1.91(1.14-3.23)$ & 0.02 & $1.29(0.78-2.14)$ & 0.32 \\
\hline Completed college & $0.98(0.76-1.27)$ & 0.89 & $0.85(0.64-1.11)$ & 0.24 \\
\hline Family history of osteoporosis & $3.44(2.59-4.56)$ & $<0.001$ & $3.71(2.68-5.15)$ & $<0.001$ \\
\hline High self-rated health status & $0.75(0.53-1.07)$ & 0.11 & $0.98(0.69-1.41)$ & 0.92 \\
\hline Increased weight (in $11.4 \mathrm{~kg}$ increments) & $0.54(0.49-0.60)$ & $<0.001$ & $0.57(0.52-0.62)$ & $<0.001$ \\
\hline Current smoking & $0.85(0.31-2.30)$ & 0.75 & $0.52(0.20-1.36)$ & 0.18 \\
\hline History of alcohol use $\geq 4$ times per week, $\geq 3$ drinks at a time & $0.36(0.16-0.80)$ & 0.01 & $0.32(0.15-0.67)$ & 0.002 \\
\hline History of oral steroid use $>1$ month & $2.20(1.44-3.35)$ & $<0.001$ & $1.86(1.17-2.94)$ & 0.01 \\
\hline Height loss $>2.54 \mathrm{~cm}$ over the lifetime & $1.64(1.29-2.08)$ & $<0.001$ & $2.08(1.61-2.68)$ & $<0.001$ \\
\hline Use of arms to get up from a chair most of time & $1.24(0.99-1.57)$ & 0.07 & $0.93(0.73-1.19)$ & 0.57 \\
\hline Fall within past 5 years & $1.50(1.20-1.88)$ & $<0.001$ & $1.50(1.19-1.89)$ & 0.001 \\
\hline History of low-trauma fracture (resulting from fall from standing height or less) & $2.52(1.87-3.41)$ & $<0.001$ & $3.16(2.22-4.50)$ & $<0.001$ \\
\hline
\end{tabular}

Receipt of osteoporosis screening was not significantly associated with risk factors of increased age, oral steroid use for $>1$ month, white race, heavy alcohol consumption, or smoking. When we repeated bivariate and multivariable logistic regression analyses for only women aged 65 and older and men age 70 and older, we found that the same variables were retained in the final multivariable model for receipt of osteoporosis screening (sex, weight, family history of osteoporosis, and history of low-trauma fracture), with the same direction of association and similar strength of association.

\section{DISCUSSION}

Our survey of 1,268 women and men aged 60 and older revealed that individuals with several known osteoporosis risk factors are not being sufficiently targeted for osteoporosis screening. Most notably, older respondents were significantly less likely than younger respondents to report receiving screening recommendations from their physicians and no more likely than younger respondents to undergo screening. This is a notable finding given that age is the strongest individual risk factor for osteoporosis, with older individuals being at highest risk. This finding that older individuals are less likely to be targeted for osteoporosis screening concurs with the finding of a large-scale study in which researchers abstracted data from the electronic medical records of patients seen in ten primary care practices, ${ }^{18}$ and highlights an important area for osteoporosis screening improvement.

In our study, the presence of several other osteoporosis risk factors-such as oral steroid use $>1$ month, low-trauma fracture, loss of height, heavy alcohol consumption, smoking, or white race —either did not make physicians more likely to recommend screening or did not make individuals more likely to undergo screening, when adjusting for other osteoporosis risk factors. Several of our results are consistent with results of earlier

Table 3. Multivariable Associations of Patient Characteristics with Osteoporosis Screening Recommendation and Receipt of Screening

\begin{tabular}{|c|c|c|c|c|}
\hline \multirow[t]{3}{*}{ Explanatory variables } & \multicolumn{4}{|l|}{ Response variables } \\
\hline & \multicolumn{2}{|c|}{$\begin{array}{l}\text { Physician recommendation for } \\
\text { osteoporosis screening }\end{array}$} & \multicolumn{2}{|c|}{$\begin{array}{l}\text { Receipt of osteoporosis } \\
\text { screeningt }\end{array}$} \\
\hline & OR $(95 \% \mathrm{Cl})$ & $P$ value & OR $(95 \% \mathrm{Cl})$ & $P$ value \\
\hline Increased age (in 5-year increments) & $0.87(0.77-0.97)$ & 0.01 & $\mathrm{NR} \ddagger$ & - \\
\hline Female sex & $11.71(8.15-16.82)$ & $<0.001$ & $9.18(6.61-12.74)$ & $<0.001$ \\
\hline White race & $2.95(1.48-5.88)$ & 0.002 & $\mathrm{NR} \ddagger$ & - \\
\hline Family history of osteoporosis & $2.10(1.43-3.10)$ & $<0.001$ & $2.26(1.48-3.43)$ & $<0.001$ \\
\hline Increased weight (in 11.4 kg increments) & $0.70(0.61-0.80)$ & $<0.001$ & $0.63(0.54-0.74)$ & $<0.001$ \\
\hline Use of arms to get up from a chair most of time & $1.56(1.08-2.25)$ & 0.02 & $\mathrm{NR} \ddagger$ & - \\
\hline History of low-trauma fracture (resulting from fall from standing height or less) & $\mathrm{NR} \ddagger$ & - & $2.05(1.29-3.23)$ & 0.002 \\
\hline Interaction term: weight $\times$ (height loss $>2.54 \mathrm{~cm}$ over the lifetime) & $\mathrm{NR} \ddagger$ & - & $1.35(1.04-1.75)$ & 0.02 \\
\hline
\end{tabular}

${ }^{*}$ Hosmer-Lemeshow goodness-of-fit test $P$ value $=0.95$, indicating adequate fit $\dagger$ Hosmer-Lemeshow goodness-of-fit test $P$ value $=0.73$, indicating adequate fit $\ddagger$ Not retained in final model 
studies. For example, our finding that individuals with a history of oral steroid use may not be receiving sufficient osteoporosis screening concurs with findings from other studies that patients taking oral steroids are underscreened. ${ }^{19,20}$ Our observation that osteoporosis screening was more likely in women than men is also consistent with earlier studies. ${ }^{18,21}$ Our finding that osteoporosis screening was no more likely in white adults than black adults, when adjusting for other osteoporosis risk factors, is different from findings of several previous studies and warrants further study. ${ }^{18,22}$

Our study suggests that physicians need to better assess older adults' osteoporosis risk and ensure that high-risk individuals receive screening. Physicians should in particular be aware that individuals with advanced age (the most elderly), height loss, history of low-trauma fracture, and oral steroid use are at increased risk of osteoporosis. Physicians should be more vigilant about osteoporosis screening in atrisk patients in general (e.g., all women over the age of 65), but pay special attention to individuals with the risk factors listed above, as our results suggest that these individuals may be particularly underscreened. Several previous studies have demonstrated that adults who undergo osteoporosis testing are more likely to receive treatment; ${ }^{23-25}$ thus, improving screening rates in individuals at greatest risk is an important step towards improving osteoporosis outcomes. The best way of improving physician identification of individuals at increased risk of osteoporosis and referral for screening is unclear. Several potential strategies to improve physicians' osteoporosis screening practices include financial incentives (e.g., incentive payments for physicians performing well on Medicare's Physician Quality Reporting Initiative (PQRI) osteoporosis screening measures), physician reminders (e.g., electronic medical record system reminders), and the use of local opinion leaders. A direct patient education media campaign may also improve screening rates-if patients are educated about risk factors, at-risk individuals may ask their physicians for screening. Further studies are needed to evaluate the efficacy of various strategies to improve osteoporosis screening rates; one recent large randomized controlled trial of physician and/or patient education to improve osteoporosis testing and treatment rates failed to show any benefit of a brief education program. $^{26}$

To our knowledge, our study is the largest survey of patient characteristics associated with osteoporosis screening. However, the study had several limitations. First, because the survey was based on self-report, there may have been recall bias concerning the receipt of screening or a screening recommendation; this is further suggested by our finding that more people reported prior screening than receiving a screening recommendation. The wording of our screening recommendation question may also have affected participants' responses; individuals who had screening recommended by a non-physician health care provider may have answered "no" to this question. Moreover, individuals whose physicians' ordered an osteoporosis screening test but did not discuss this with the patient may not have considered this a recommendation. Another limitation of our study is that the survey population consisted of individuals who lived in or near western Pennsylvania, volunteered for a research registry, and were disproportionately white, healthy, and highly educated, which may limit the generalizability of our results. However, if in this survey population individuals with several known osteoporosis risk factors were not more likely to receive a screening recommendation or screening, this may be an even larger problem in the general population of older adults. Furthermore, our choice of a 1-month cutoff for oral steroid use associated with increased risk of osteoporosis is shorter than the 3-month steroid use duration put forth in several guidelines. ${ }^{11,13}$ Although there is evidence that any oral steroid use increases osteoporosis risk, ${ }^{27}$ our choice of a 1-month cutoff was arbitrary, and we may have found different results had we chosen a longer steroid use duration. Finally, our survey did not capture all of the variables related to physician recommendation of screening or prior screening; for example, we did not assess body mass index, whether participants had a regular primary care physician, had health insurance, were physically active, or had comorbidities, which are likely related to osteoporosis screening. Our study also had several notable strengths, including a large sample size, nearly $70 \%$ response rate, inclusion of both female and male participants, and inclusion of key risk factors in recently published guidelines for osteoporosis prevention and treatment. ${ }^{11,13}$

In conclusion, we found that individuals with several osteoporosis risk factors, such as advanced age, oral steroid use $>1$ month, loss of height, and history of low-trauma fracture were either not more likely to receive osteoporosis screening recommendations or not more likely to undergo screening, when adjusting for other osteoporosis risk factors. Our study points to the need for physicians to better assess older adults' osteoporosis risk, recommend screening to individuals at risk, and follow-up with screening for at-risk individuals. Improving screening rates in individuals at greatest risk for osteoporosis is an important step towards improving health outcomes.

Acknowledgments: The authors gratefully thank Anna K. Ercius, MPH, for mailing surveys, data collection, and data entry; Deljo Gannon for data entry and validation; Linda Buinn and Terry Sefcik, MSIS, for assistance with survey design; the University of Pittsburgh Claude D. Pepper Older Americans Independence Center for access to a registry of individuals interested in research participation; and all of the individuals who responded to our survey.

Funding/Support: This study was supported by grants KL2 RRO24153 and UL1 RR024153 from the National Center for Research Resources (NCRR), a component of the National Institutes of Health (NIH) and NIH Roadmap for Medical Research (Dr. Nayak); grant K24 DK062895 from the National Institute of Diabetes and Digestive and Kidney Diseases (Dr. Greenspan); and grant P3O AG024827 from the National Institute on Aging (University of Pittsburgh Claude D. Pepper Older Americans Independence Center). The contents of this manuscript are solely the responsibility of the authors and do not necessarily represent the official view of the NCRR or NIH.

\section{Conflict of Interest: None disclosed.}

Corresponding Author: Smita Nayak, MD; University of Pittsburgh, 200 Meyran Ave., Suite 20, Pittsburgh, PA 15213, USA (email: nayaks@upmc.edu).

\section{REFERENCES}

1. U.S. Department of Health and Human Services. Bone health and osteoporosis: a report of the surgeon general. Rockville, MD: U.S. 
Department of Health and Human Services, Office of the Surgeon General; 2004

2. Looker AC, Orwoll ES, Johnston CC Jr., et al. Prevalence of low femoral bone density in older U.S. adults from NHANES III. J Bone Miner Res. 1997; 12: 1761-8.

3. Burge R, Dawson-Hughes B, Solomon DH, et al. Incidence and economic burden of osteoporosis-related fractures in the United States, 2005-2025. J Bone Miner Res. 2007; 22: 465-75.

4. Nelson HD, Helfand M, Woolf SH, Allan JD. Screening for postmenopausal osteoporosis: a review of the evidence for the U.S. Preventive Services Task Force. Ann Intern Med. 2002; 137: 529-41.

5. Nguyen TV, Eisman JA, Kelly PJ, Sambrook PN. Risk factors for osteoporotic fractures in elderly men. Am J Epidemiol. 1996; 144: 255-63.

6. Huddleston JM, Whitford KJ. Medical care of elderly patients with hip fractures. Mayo Clin Proc. 2001; 76: 295-8.

7. Braithwaite RS, Col NF, Wong JB. Estimating hip fracture morbidity, mortality and costs. J Am Geriatr Soc. 2003; 51: 364-70.

8. Nevitt MC, Ettinger B, Black DM, et al. The association of radiographically detected vertebral fractures with back pain and function: a prospective study. Ann Intern Med. 1998; 128: 793-800.

9. Oleksik A, Lips P, Dawson A, et al. Health-related quality of life in postmenopausal women with low BMD with or without prevalent vertebral fractures. J Bone Miner Res. 2000; 15: 1384-92.

10. Cummings SR, Nevitt MC, Browner WS, et al. Risk factors for hip fracture in white women. Study of Osteoporotic Fractures Research Group. N Engl J Med. 1995; 332: 767-73.

11. Kanis JA on behalf of the World Health Organization Scientific Group. Assessment of Osteoporosis at the Primary Health Care Level. 2008 Technical Report. University of Sheffield, UK: WHO Collaborating Center; 2008.

12. Screening for osteoporosis in postmenopausal women: recommendations and rationale. Ann Intern Med. 2002;137:526-8.

13. The National Osteoporosis Foundation (NOF). Clinician's Guide to prevention and treatment of osteoporosis. Washington, DC: National Osteoporosis Foundation; 2008.

14. Gaseem A, Snow V, Shekelle P, et al. Screening for osteoporosis in men: a clinical practice guideline from the American College of Physicians. Ann Intern Med. 2008; 148: 680-4.
15. Kiebzak GM, Beinart GA, Perser K, et al. Undertreatment of osteoporosis in men with hip fracture. Arch Intern Med. 2002; 162: 2217-22.

16. Morris CA, Cabral D, Cheng $\mathbf{H}$, et al. Patterns of bone mineral density testing: current guidelines, testing rates, and interventions. J Gen Intern Med. 2004; 19: 783-90.

17. Gehlbach SH, Fournier M, Bigelow C. Recognition of osteoporosis by primary care physicians. Am J Public Health. 2002; 92: 271-3.

18. Solomon DH, Brookhart MA, Gandhi TK, et al. Adherence with osteoporosis practice guidelines: a multilevel analysis of patient, physician, and practice setting characteristics. Am J Med. 2004; 117: 919-24.

19. Curtis JR, Westfall AO, Allison JJ, et al. Longitudinal patterns in the prevention of osteoporosis in glucocorticoid-treated patients. Arthritis Rheum. 2005; 52: 2485-94.

20. Shah SK, Gecys GT. Prednisone-induced osteoporosis: an overlooked and undertreated adverse effect. J Am Osteopath Assoc. 2006; 106: 6537.

21. Morris CA, Cheng H, Cabral D, Solomon DH. Predictors of screening and treatment of osteoporosis: a structural review of the literature. Endocrinologist. 2004; 14: 70-5.

22. Miller RG, Ashar BH, Cohen J, et al. Disparities in osteoporosis screening between at-risk African-American and white women. J Gen Intern Med. 2005; 20: 847-51.

23. Solomon $\mathbf{D H}$, Morris C, Cheng $\mathbf{H}$, et al. Medication use patterns for osteoporosis: an assessment of guidelines, treatment rates, and quality improvement interventions. Mayo Clin Proc. 2005; 80: 194-202.

24. Marci CD, Anderson WB, Viechnicki MB, Greenspan SL. Bone mineral densitometry substantially influences health-related behaviors of postmenopausal women. Calcif Tissue Int. 2000; 66: 113-8.

25. Fitt NS, Mitchell SL, Cranney A, et al. Influence of bone densitometry results on the treatment of osteoporosis. CMAJ. 2001; 164: 777-81.

26. Solomon DH, Katz JN, Finkelstein JS, et al. Osteoporosis improvement: a large-scale randomized controlled trial of patient and primary care physician education. J Bone Miner Res. 2007; 22: 1808-15.

27. van Staa TP, Leufkens HG, Abenhaim L, Zhang B, Cooper C. Oral corticosteroids and fracture risk: relationship to daily and cumulative doses. Rheumatology(Oxford). 2000; 39: 1383-9. 


\section{APPENDIX}

Osteoporosis Survey Questions

The survey contained 44 questions in all; the following are items relevant to this manuscript.

1. How old are you? years

2. Have you lost any height (shrunk) over the years? $\square$ Yes $\square$ No If you have lost height, how many inches?

3. How much do you weigh? pounds

4. In general, would you say that your health is: $\quad \square$ Excellent $\quad \square$ Very good $\square$ Good $\quad \square$ Fair $\quad \square$ Poor

5. Have you ever used prednisone or another steroid pill (for example, medrol) for longer than 1 month? $\square$ Yes $\square$ No

6. Are you currently a smoker? $\square$ Yes $\square$ No

7. How often do you have a drink containing alcohol?

$\square$ Never (skip next question) $\quad \square 2$ to 3 times a week

$\square$ Monthly or less $\square 4$ or more times a week

$\square 2$ to 4 times a month

8. How many drinks containing alcohol do you have on a typical day when you are drinking?

$\square 1$ or $2 \square 3$ or $4 \quad \square 5$ or $6 \quad \square 7,8$, or $9 \quad \square 10$ or more

9. Do you usually (most of the time) need your arms to assist you in standing up from a chair? $\square$ Yes $\square$ No

10. Have you fallen within the past 5 years? $\square$ Yes $\square$ No

11. Have you ever had a fracture (broken bone)? $\square$ Yes $\square$ No

If your answer is yes:

Which bone(s) did you break? (Check all that apply.) At what age?

Bone broken: Age (in years):

$\square$ Hip

$\square$ Wrist

$\square \quad$ Spine (back, vertebrae)

$\square \quad$ Rib

$\square$ Pelvis

$\square$ Other(s)

(please specify)

How did you break each bone? (Check all that apply.)

Indicate bone(s) broken this way:

$\square$ Fall from standing height or less (example: tripped and fell)

$\square$ Fall from greater than standing height (example: from ladder)

$\square$ Accident (examples: car, bicycle)

$\square$ Sports injury (please describe)

$\square$ Other (please explain)

12. Have you ever heard of osteoporosis (a medical condition of thin bones that break easily)? $\square$ Yes $\quad \square$ No

13. Has your doctor ever recommended that you be screened or tested for osteoporosis? $\square$ Yes $\quad \square$ No

14. Have you ever had an osteoporosis test done? $\square$ Yes $\quad \square$ No

If your answer is yes, what kind of test was it? (Select all that apply.)

$\square$ Dual energy X-ray absorptiometry (DXA or DEXA) $\square$ Questionnaire

$\square$ Heel ultrasound

$\square$ Other (please describe)

$\square$ CT scan

15. Have you ever been diagnosed with osteoporosis? $\square$ Yes $\square$ No

16. Do you have a family history of osteoporosis? $\square$ Yes $\square$ No

If your answer is yes, which relative(s) have had osteoporosis? (Check all that apply.)

$\square$ Mother $\square$ Father $\square$ Sister $\square$ Brother $\square$ Grandmother $\square$ Other (please specify)

17. What is your sex? $\square$ Female $\square$ Male

18. What is your race/ethnicity?

$\square$ American Indian or Alaska Native

$\square$ Asian

$\square$ Black or African American

$\square$ Native Hawaiian or Other Pacific Islander

$\square$ White

$\square$ Other (please specify)

Are you Hispanic or Latino? $\quad \square$ Yes $\quad \square$ No

19. What is the highest educational level you completed?

$\square$ Less than high school

$\square$ High school or General Educational Development (GED) certification 